\title{
Learning Process Using WhatsApp Media: Effectiveness Analysis Makes Agreements in the Group Learning Process
}

\author{
Erik Saut H Hutahaean ${ }^{1}$, Rini Indryawati ${ }^{2}$, Maria Chrisnatalia ${ }^{3}$ \\ 1Universitas Bhayangkara Jakarta Raya, Jakarta-Indonesia, $\square$ (e-mail) erik.saut@dsn.ubharajaya.ac.id \\ 2Universitas Gunadarma, Jakarta-Indonesia, , $\square$ (e-mail) rini_indry@yahoo.com \\ 3Universitas Gunadarma, Jakarta-Indonesia, , $\square$ (e-mail) mariachrisnatalia@gmail.com
}

\begin{abstract}
Technology is an effective means to facilitate the learning communication process, but there are still many people who are familiar with the process of direct communication. This study intends to analyze the effectiveness of using WhatsApp in carrying out tasks. Three students were involved in a simple experiments, the task was to make an agreement on the list of important items brought. The data obtained are in the form of communication transactions that occur during discussions. This study found a low score in making decisions about the order of items that were important to be carried, and there was a discussion over the time limit. Another results show that there are conversations that are not balanced and not relevant to their purpose. One dominates the other two passive, there is a chat that is not in line with the direction of discussion.
\end{abstract}

Keywords: computer mediated communication, communication completing tasks, effectiveness of learning outside the classroom.

\section{Introduction}

The learning process has undergone, there has been an update on how to do learning, although currently it is still in the process of transition in implementing it. Learning from the beginning was done through face-to-face interaction, but now many have done it using computer media (Bouhnik \& Deshen, 2014). The learning process is connected through an internet protocol, everyone meets on social media. Social media has the potential to change social life, which is to make people engage more time to use online communication tools (Baruah, 2012). 
One of the social media used is WhatsApp, a social media application that facilitates its users to do textual, image, sound and soft file interactions. WhatsApp is widely used for group learning (Alsaleem, 2013). the advantage of this application is a feature that can improve communication within a group. The results of research on the use of WhatsApp as a learning media, show that there are indications that learning outcomes help students more actively convey information and explore the meaning of learning (Jain, 2016). Students can send and share files, and even link links that are references to the learning process.

Computer mediated communication has two effects, supporting the intensity of communication or even weakening the face-to-face communication function (Barkhi, Jacob, \& Pirkul, 1999). Using social media as an online learning media tool will indeed provide additional, more flexible free time to explore more about the reliability of learning mastery. But it cannot fully accommodate other interaction patterns, compared to face-to-face communication patterns. Computer equipment and internet networks used are two things that cause communication disruption. Some researchers have argued that computer information technology is not able to precisely mimic the characteristics of faceto-face communication (Rhoads, 2010). Whereas research results show that social media has a positive potential for learning (Susilo, 2014)

This study intends to conduct an analysis of the use of CMC for group learning processes, focused on completing the task of making decision decisions, which are part of the learning task. The results of the study can be used for educators and instructors of learning to choose or design the use of social media WhatsApp as a learning tool, especially related to the completion of tasks that form the soft competency of decision making in learning groups.

\section{Method}

Research was conducted on three students, involved to participate in one study group. Subjects are given the task of discussing the priority items, the assignments given are part of the course assignments given by the Lecturer. The outcome of their assignment is an agreed decision about the list of items that have been sorted. Subjects are given instructions on creating groups on CMC (WhatsApp). All participant gets the same rights to interact to convey their views. The discussion was given 60 minutes, including making an agreement. The analysis was carried out on all chats (text information) delivered during the discussion. The data were analyzed quantitatively. Conversation content is divided into five parts. The category consists of the length of the discussion process, the number of conversations, agreement sentences, and the final value of the discussion. Effectiveness is known through the conclusion score, and is seen in relation to the duration used, the number of conversations and the variation of agreement sentences.

\section{Results and Discussion}

The most common interaction using computer media is interaction through the sending of text (Walther, 2011), in the world of CMC known as chat. Each participant who joined the interaction group had the same opportunity to send the text. In this study, there were 288 chat, cumulative chat from three subjects involved in the study. Subject 1 did 139 chat, and dominated the number of chat (see Table 1.). Subject 1 contributed as much as 48 percent in making an agreement. The effort issued by subject one was 0.48 , the role he performed was at levels above average. Subject 2 and Subject 3 their roles are below average. Interactions that occur during group learning are dominated by Subject 1 , and Subjects 2 and 3 play a less active role. CMC is very possible for unlimited communication patterns to occur, such as limits on social positions. Unlimited communication patterns make certain people free to express themselves in the process of group discussion, and others are hampered. But if one party dominates, an unbalanced interaction will occur. 
Table.1. Chat Participation

\begin{tabular}{lccccccc}
\hline Partisipation & $\begin{array}{c}\text { Chat } \\
\text { Total }\end{array}$ & Ratio & Total Gap & $\begin{array}{c}\text { Chat } \\
\text { Gap S1 }\end{array}$ & $\begin{array}{c}\text { Chat } \\
\text { Gap S2 }\end{array}$ & $\begin{array}{c}\text { Chat } \\
\text { Gap S3 }\end{array}$ & $\begin{array}{c}\text { Standard } \\
\text { Deviation } \\
\text { Area }\end{array}$ \\
\hline Chat Total & 288 & - & - & - & - & - & 1SD \\
Chat S1 & 139 & $1: 0.48$ & 149 & - & - & - & 1SD \\
Chat S2 & 95 & $1: 0.33$ & 193 & 54 & - & - & $-1 S D$ \\
Chat S3 & 54 & $1: 0.19$ & 234 & 95 & 41 & - & $-1 S D$ \\
\hline
\end{tabular}

There is no balance between roles and participatory roles in making agreements. Found there is an impulsive interaction pattern, just follow it, and run it by mentioning an agreement. The word 'ok' was mostly sent by all participants, the amount reached 56 percent if put together with the other words (Table 2). The percentage of occurrence of the agreement word is quite large (85: 288), which is as much as 29 percent of the total chat. The keyword that is called is the word variance, the search results are 9 variants of the word agreement (see Table 2), of the 9 variants found there is one word that is very common in impulsivity in making an agreement, in the form of chat 'follow'. The loss of social boundaries within the CMC can lead users to become more impulsive, and patterns that are inconsistent (DeAndrea \& Walther, 2011). The formation of social boundaries in the interaction process is seen through a passive role run by Subject 2 and Subject 3.

Decisions made based on impulsivity are proven to ignore the search for true goals, and to highlight the attitude of togetherness. Desires that arise are judged to have cohesiveness in the group, and the desire to avoid positioning within the group. Based on the unity side, the group looks compact, but the results obtained are not optimal. This can be seen through the many mentioning 'ok', the mention of it is very dominating in making an agreement its dominance is more than half the appearance of the agreement. The discussion took place smoothly, all participants tended to be easy to approve decisions proposed by participants. Research explaining the interaction process using CMC shows that the conditions that occur within it can moderate the influence of emerging social feelings (Monzani, Ripoll, Peiró, \& Van Dick, 2014).

An interaction pattern is dominated by S1. The first is the domination of chat done by the subject 1. The second domination of writing 'ok' that occurs in making an agreement. It turns out that the dominance of subject 1 cannot reflect the role of leader in the group, because there is an ineffective interaction. Likewise, the large number of 'ok' writings used to make agreements agree, cannot be considered to represent strong cohesiveness within the group. But instead it shows the throwing of responsibility towards one subject to give ideas, so that the overall interaction makes one subject dominate chat, the impact of the agreement making process is not effective. Because the willingness to chat is higher on one subject, as a result other subjects become passive. This passive state illustrates the low desire to chat (Seyyedrezaei \& Ziafar, 2014).

Tabel. 2. Agreement Word List

\begin{tabular}{lcc}
\hline Agreement Word & Total & Percentage \\
\hline Sepakat & 4 & $5 \%$ \\
Deal & 3 & $3 \%$ \\
Setuju & 9 & $10 \%$ \\
Ok & 47 & $55 \%$ \\
Oke & 6 & $7 \%$ \\
Okay & 6 & $7 \%$ \\
Ketok Palu & 1 & $1 \%$ \\
Ngikut & 8 & $9 \%$ \\
Conclusion & 1 & $1 \%$ \\
\hline
\end{tabular}


The time limit for discussion that is only 60 minutes cannot be used effectively by the group. The decision to agree can be completed with 94 minutes, so the use of ineffective time is 36 percent. This time surplus illustrates the occurrence of chat interactions that are not in line with the purpose of the task, there is interaction outside the context, not discussing the making of agreement. The outcome of the tasks carried out by the participants is to produce a sequence of decisions, and then the order is given a score according to the standard guidelines. The result is the score that can be obtained by the group is 78 , and is included in the low category. There is a discrepancy in the sequence decided by the group, in the order that is in the assessment guidelines, so that the scores obtained by the group become large. Between the past duration of 60 minutes and the low score, it can be used to explain the occurrence of a discussion process that runs ineffectively, the occurrence of excess time and scores in the low category become clear instructions to prove it.

Tabel.3. Source of Score and Categorization

\begin{tabular}{lcc}
\hline Total Score Sources & Total Score & Catgorical \\
\hline Discussion Score & $* 78$ & Low \\
Agreement Words & 85 & Many \\
Sum of Chat & 288 & Many \\
Discussion Duration & 94 Minutes & Over Time ( $>60$ Minute) \\
\hline${ }^{*}$ if it gets bigger, it can be assumed that there is a difference that increases with the actual order.
\end{tabular}

Making a decision in the group learning process becomes ineffective because of the throwing of responsibility, this happens because there is a dominating role during the discussion process. The symptom that can represent it is the implementation of the discussion that goes beyond the time limit and the decision score that is categorized as low. The duration of the discussion that passes from the time limit, due to the interaction outside the context of the task.

\section{Conclusions}

The discussion process to make decisions using CMC can be ineffective. The reality that occurs in it is the emergence of an unbalanced role to convey information, and the occurrence of an impulsive response in making an agreement. An unbalanced communication role of each member contributes to the ineffectiveness of the discussion process. It is clear that the use of social media technology is not the cause of the ineffectiveness of discussion, precisely the impulsive response in discussion makes many agreed agreements and conclusions ineffective.

WhatsApp has provided facilities with a sound approach, so that users can use it more text based, and also have multi-media (Aal, Parmar, Patel, Dhrubo, \& Sen, 2014) based. Subjects in this study have not utilized the multi-media base to discuss and make agreements. There may be certain people who are hampered in written verbal matters, which are caused by social backgrounds and habits (Hilte, Vandekerckhove, \& Daelemans, 2018). In the future, research on the use of WhatsApp as learing media needs to involve the use of the multimedia features contained in it, and socio-culutral background of the participant.

\section{Acknowledgments}

Our gratitude for students who have been willing to be involved as research subjects, as well as for Dr. Matrisya who has provided an opportunity so that we get the time to analyze the communication process through CMC in a process of working on group assignments. Thanks to Dr. Doni, for teaching about how to use the reference manager application.

Everything that we have gotten from all parties really helps us in realizing the implementation of this article. We feel the help of all of you is very helpful to gain understanding and foster efforts to complete this paper. 


\section{References}

Aal, L. B., Parmar, J. N., Patel, V. R., Dhrubo, P., \& Sen, J. (2014). Whatsapp , Skype , Wickr , Viber , Twitter and Blog are Ready to Asymptote Globally from All Corners during Communications in Latest Fast Life, 6(June), 101-116.

Alsaleem, B. I. A. (2013). The Effect of" WhatsApp" Electronic Dialogue Journaling on Improving Writing Vocabulary Word Choice and Voice of EFL Undergraduate Saudi Students. Arab World English Journal, 4(3), 213-225.

Barkhi, R., Jacob, V. S., \& Pirkul, H. (1999). An Experimental Analysis of Face to Face versus Computer Mediated Communication Channels. Group Decision and Negotiation, 8(4), 325-347. https://doi.org/10.1023/A:1008621423120

Baruah, T. D. (2012). Effectiveness of Social Media as a tool of communication and its potential for technology enabled connections: A micro-level study. International Journal of Scientific and Research Publications, 2(1), 1-10. https://doi.org/ISSN 2250-3153

Bouhnik, D., \& Deshen, M. (2014). WhatsApp Goes to School: Mobile Instant Messaging between Teachers and Students. Journal of Information Technology Education: Research, 13, $217-231$. https://doi.org/10.28945/2051

DeAndrea, D. C., \& Walther, J. B. (2011). Attributions for inconsistencies between online and offline self-presentations. Communication Research, 38(6), 805-825. https://doi.org/10.1177/0093650210385340

Hilte, L., Vandekerckhove, R., \& Daelemans, W. (2018). Social Media Writing and Social Classø: A Correlational Analysis of Adolescent CMC and Social Background. International Journal of Society, Culture \& Language., 6(2), 73-89.

Jain, J. (2016). Learning Beyond the Walls: The Role of WhatsApp Groups. In Envisioning the Future of Online Learning. Springer, Singapore., (pp. 447-457).

Monzani, L., Ripoll, P., Peiró, J. M., \& Van Dick, R. (2014). Loafing in the digital age: The role of computer mediated communication in the relation between perceived loafing and group affective outcomes. Computers in Human Behavior, 33, 279-285. https://doi.org/10.1016/j.chb.2014.01.013

Rhoads, M. (2010). Face-to-face and computer-mediated communication: What does theory tell us and what have we learned so far? Journal of Planning Literature, 25(2), 111-122. https://doi.org/10.1177/0885412210382984

Seyyedrezaei, S. H., \& Ziafar, M. (2014). The Relationship between Computer Mediated Communication ( CMC ) and Willingness to Communicate ( WTC ). Journal of Language Sciences $\mathcal{E}$ Linguistics, 2(1), 21-26.

Susilo, A. (2014). Exploring Facebook and Whatsapp As Supporting Social Network Applications For English Learning In Higher Education. Teaching and Learning in the 21st Century: Challenges for Lecturers and Teachers, 10-24.

Walther, J. B. (2011). Theories of computer-mediated communication and interpersonal relations. The SAGE Handbook of Interpersonal Communication, 443-479. Retrieved from http://commres.net/wiki/_media/42241_14.pdf\%0Ahttp://scholar.google.com/scholar?hl=en\&btn $\mathrm{G}=$ Search\&q=intitle:Theories+of+Computer+Mediated+Communication+and+Interpersonal+Relations \#0 